Binghamton University

The Open Repository @ Binghamton (The ORB)

2014

\title{
A Thoreauvian Account of Prudential Value
}

Christopher Morgan-Knapp

c.morgan-knapp@binghamton.edu

Follow this and additional works at: https://orb.binghamton.edu/philosophy_fac

Part of the Philosophy Commons

\section{Recommended Citation}

Morgan-Knapp, Christopher, "A Thoreauvian Account of Prudential Value" (2014). Philosophy Faculty Scholarship. 26.

https://orb.binghamton.edu/philosophy_fac/26

This Article is brought to you for free and open access by the Philosophy at The Open Repository @ Binghamton (The ORB). It has been accepted for inclusion in Philosophy Faculty Scholarship by an authorized administrator of The Open Repository @ Binghamton (The ORB). For more information, please contact ORB@binghamton.edu. 


\title{
A THOREAUVIAN ACCOUNT OF PRUDENTIAL VALUE
}

\author{
Christopher Morgan-Knapp \\ Binghamton University
}

\begin{abstract}
This article develops and defends an account of prudential value and disvalue that is constructed out of ideas found in Thoreau's Walden. The core claim is that prudential value consists in responding appropriately to those things that make the world better, and that prudential disvalue consists in encountering those things that make it worse. The core argument is that responding appropriately to objective value and avoiding objective disvalue are our aims in so far as we are evaluative creatures, and that our evaluative nature is fundamental in the context of inquiring into our own good. I conclude by discussing respects in which the Thoreauvian account improves upon some alternative accounts of well-being.
\end{abstract}

Henry David Thoreau has not left much of a mark on contemporary analytic philosophy. This is not terribly surprising. We typically prize clarity and argumentative rigor. And though the virtues of Thoreau's writing are many, clarity and rigor are not among them. Indeed, Thoreau seems not only to be aware of this, but to revel in it. Near the end of Walden, he writes:

It is a ridiculous demand which England and America make, that you shall speak so that they can understand you. Neither men nor toadstools grow so. As if that were important.... As if there were safety in stupidity alone. I fear chiefly lest my expression may not be extravagant enough, may not wander far enough beyond the narrow limits of my daily experience, so as to be adequate to the truth of which I have been convinced.(324) ${ }^{1}$

\footnotetext{
${ }^{1}$ Parenthetical page numbers for quotations from Walden refer to Henry D. Thoreau, Walden (Princeton: Princeton University Press, 1989).
} 
It is as if Thoreau is anticipating the development of analytic philosophy, and wants to give it a preemptive poke in the eye.

Provocative though it may be, I urge that contemporary philosophers take this repudiation of their methodology as a challenge, and not as a sign of some fundamental incompatibility between their intellectual interests and his. It is no trivial matter to understand Thoreau as a participant in contemporary philosophical debates, but he does have quite a bit to offer. At least some of his views admit of clear expression and reasoned support. And at least some of the positions and arguments that can be gleaned from his work can contribute to current philosophical research.

My goal here is to show that this is so with respect to one particular aspect of Thoreau's views: his account of prudential value. I proceed as follows: I begin by extracting an account of prudential value from Walden. Then, in Section 2, I supplement this account with a Thoreauvian account of prudential disvalue. Section 3 develops an argument in favor of Thoreau's position. And I conclude in Section 4 by commenting on how Thoreau's position relates to, and how it improves upon, some contemporary alternatives.

\section{$\S 1$. Prudential Value}

Prudential value is the value in terms of which a person's quality of life is measured. It is the value that determines how well her life is going for her. To give an account of prudential value is thus to explain the nature of the states that make an intrinsic contribution to one's self-interest. As such, an account of prudential value is a fundamental piece of an account of well-being.

Prudential value can be contrasted with what I will call 'objective value', or often just plain 'value.' Objective value is the agent-neutral value in terms of which we evaluate the world. It is the value that determines how good the world is from a general point of view, as opposed to how good it is for a particular person. As such, it figures prominently in accounts of moral rightness, and in particular, versions of consequentialism. 
Some prominent contemporary accounts of prudential value identify it with particular mental states such as pleasure, others with the satisfaction of particular desires, still others with a list of goods such as autonomy, knowledge, and close personal relationships. Thoreau's account is different from all of these. Thoreau holds that our lives are to be evaluated in terms of our encounters with, and responses to, what is objectively valuable. The more we encounter value and respond appropriately to it, the better our life is.

This, at any rate, is a reading of Thoreau that fits with, and helps to make sense of, a good deal of what he says about good and bad lives. Before we look at some representative passages, though, it is useful to keep in mind that when Thoreau recommends some aspect of a life, he may do so either intrinsically or instrumentally. Sometimes, that is, Thoreau might endorse doing or being something because doing or being that thing is itself part of what makes a life good. Alternatively, Thoreau might endorse doing or being something as a means to achieving something else that is part of a good life. This instrumental value that some activities or ways of being have is derivative - it is due to these things bearing some promotional relationship (e.g. being reliable means to, being efficient means to, being necessary for) to something else that is intrinsically valuable. Merely instrumentally valuable things aren't themselves part of what a good life consists in.

Let us begin with one of the few passages in Walden that directly refers to the value at which our lives should aim and in terms of which they are to be evaluated - the "chief end" or goal of living.

I went to the woods because I wished to live deliberately, to front only the essential facts of life, and see if I could not learn what it had to teach, and not, when I came to die, discover that I had not lived. I did not wish to live what was not life, living is so dear; nor did I wish to practise resignation, unless it was quite necessary. I wanted to live deep and suck out all the marrow of life, to live so sturdily and Spartan-like as to put to rout all that was not life, to cut a broad swath and shave close, to drive life into a corner, and reduce it to its lowest terms, and, if it proved to be mean, why then to get the whole and genuine meanness of it, and publish its meanness to the world; or if it were sublime, to know it by experience, and be able to give a true account of it in 
my next excursion. For most men, it appears to me, are in a strange uncertainty about it, whether it is of the devil or of God, and have somewhat hastily concluded that it is the chief end of man here to "glorify God and enjoy him forever." (90-91, emphasis in original)

This passage begins with a mix of instrumental and intrinsic endorsements. In the first sentence, for instance, Thoreau says that he aspires to live "deliberately" so that he can achieve the end of "learning what life had to teach" him. By consciously focusing his attention on certain things, he hopes to achieve the intrinsically valuable end of understanding. And in the third sentence, he aspires to living "sturdily" so that he might have an intrinsically valuable experience of the sublimity that life contains.

The passage concludes with a somewhat cryptic reference to the Westminster Catechism's idea that our goal is to glorify and enjoy God. As I read it, when Thoreau says that this widely professed conclusion has been "somewhat hastily" arrived at, he is pointing out that this belief does not fit comfortably with the outlooks of many who hold it. These people say their aim to glorify and enjoy God, but it is not clear to Thoreau that they are persuaded that the life God gave them to live is sublime rather than dreary. "The mass of men lead lives of quiet desperation," he says. "What is called resignation is confirmed desperation." (8) Though these people are likely to affirm that the point of life is to be in an uplifting relationship to God, their attitudes of despair, dejection and resignation suggest that, from what they know of it, God and God's creation are "ordinary and mean" (332) rather than noble.

On this interpretation, Thoreau does not reject the idea that our goal is to glorify and enjoy God. His complaint is not with this conclusion, but with the fact that many who hold it do so only superficially, and perhaps contrary to the evidence that their way of life has made accessible to them. Still, the fact that he does not explicitly affirm the doctrine suggests that he is not comfortable officially signing on to this bit of orthodoxy. I suggest, then, that Thoreau thinks that there is something right about the idea that the aim of life is to glorify and enjoy God, but that there is also something about endorsing this particular formulation that could be misleading. 
Before speculating about what prevents Thoreau from affirming the Protestant view of our goal, it is worth summing up what this passage has revealed so far. The candidates for intrinsic value include: understanding what life has to offer; the experience of sublimity; and the enjoyment and glorification of God. All of these include attitudes or activities that are part of our lives as beings that can respond to value. Understanding, experiencing, enjoying and glorifying are all ways that we can and do relate to things that we take to be noble or worthy.

So why is Thoreau so ambiguous about our goal being to enjoy and glorify God? One good answer is that, as part of a catechism, this view smacks of religious doctrine. Tradition, religious and otherwise, is not something that Thoreau holds in high esteem. His concerns are many: conventional opinion can be mistaken; it can be limiting; it can be stifling; it can encourage reliance on authority rather than autonomous personal inquiry. "No way of thinking or doing, however ancient," he says, "can be trusted without proof." (8) And a catechism is little more than a list of conclusions in want of arguments. Given this, Thoreau would not have wanted to risk appearing as if he was falling back on the authority of the Church, especially on such an important issue.

Rather than rely on received opinion, he advises,

Let us settle ourselves, and work and wedge our feet downward through the mud and slush of opinion, and prejudice, and tradition, and delusion, and appearance, that alluvion which covers the globe, through Paris and London, through New York and Boston and Concord, through Church and State, through poetry and philosophy and religion, till we come to a hard bottom and rocks in place, which we can call reality, and say, This is, and no mistake. (97-98)

Here again, Thoreau offers us an instrumentally valuable way of living, and then justifies it in terms of something intrinsically valuable. Indeed, the instrumental and intrinsic recommendations echo and expand on what we have already heard. Where earlier he enjoins us to front only the essential facts, here he puts it in terms of actively clearing away what is inessential, or mere appearance. And as before, the goal involves coming to understand - before the payoff was an 
understanding of what life could teach us, whereas here the understanding that justifies the effort is more specific. What life has to teach us is what is "real."

To say that life can teach us what is "real," however, can seem perilously close to triviality. If one may learn only what is true, and what is true is real, then one cannot possibly learn anything but what is real. But Thoreau is not using "real" and "reality" to refer to all that is the case. Instead, what deserves being called "real," as Thoreau uses the word, is only what is valuable: "When we are unhurried and wise," he explains, "we perceive that only great and worthy things have any permanent and absolute existence, that petty fears and petty pleasures are but the shadow of the reality." (95-96) And again, "The greatest gains and values .... are the highest reality." (216) Putting all this together, then, our chief end involves learning what life has to teach, what life has to teach is what is real, and what is real is what is valuable.

At this point, it may seem that the chief end of our lives is decidedly intellectual: what we are to do is to gain knowledge or understanding. While there is some truth in this, it would be a mistake to imagine that Thoreau's vision of a good life involves a cool mastery of the way things are. What saves the good life from being one of sterile detachment is the fact that the target of the understanding we are to aim at is value. For when one understands what is real or valuable in the way that Thoreau has in mind, one will be anything but detached.

... reality is fabulous. If men would steadily observe realities only, and not allow themselves to be deluded, life, to compare it with such things as we know, would be like a fairy tale and the Arabian Nights' Entertainments. If we respected only what is inevitable and has a right to be, music and poetry would resound along the streets. When we are unhurried and wise, we perceive that only great and worthy things have any permanent and absolute existence, that petty fears and petty pleasures are but the shadow of the reality. This is always exhilarating and sublime. (9596)

Clearly, on Thoreau's view, one cannot understand what is valuable without rejoicing in it. What is perhaps less obvious is that the desirable attitudes to what is valuable will not only involve largely reactive attitudes like being captivated, being 
exhilarated or being awed, it will also involve active responses. To be sure, the more intellectual responses of understanding, observing, and respecting value are active in a sense. Such responses are not things that happen to one, they are things one does. Still, they are primarily reactive rather than creative: the valuable thing is in front of us, and our job is to have the appropriate reaction to it. But Thoreau's view of our goal involves even more than this. A life lived in a proper relationship to what is valuable will also be creative - one will respond to value by making music and poetry. A proper relationship to value will be inspired; one who has it will be both witness and participant.

Thoreau makes the creative aspect of the appropriate relationship to value clear in his discussions of work. Though contemplation figures prominently in Walden, so do activities like building and farming. Certainly, some discussions of these activities are instrumental. But at other points, Thoreau calls attention to the intrinsic value productive work can have. Walden is, of course, a literary as well as philosophical work, so it is not hard to believe that Thoreau, who dedicated so much effort to creating meticulous prose poems about the natural world, should consider artistic productivity an intrinsically valuable enterprise. Indeed, his view seems to be that creating things of value is a precondition of properly appreciating the valuable artistic creations of others. "The works of the great poets have never yet been read by mankind, for only great poets can read them."

But his praise is not confined to such lofty and esoteric endeavors:

I would not be one of those who will foolishly drive a nail into mere lath and plastering; such a deed would keep me awake nights. Give me a hammer, and let me feel for the furring. Do not depend on the putty. Drive a nail home and clinch it so faithfully that you can wake up in the night and think of your work with satisfaction-- a work at which you would not be ashamed to invoke the Muse. So will help you God, and so only. Every nail driven should be as another rivet in the machine of the universe, you carrying on the work. (330)

Here, the relatively prosaic craft of building provides the metaphor for good work. And it is the process as well as the result that can be valuable. In "carrying on the 
work of the universe" with our worthwhile endeavors, we are participating in the kind of valuable processes that at other times he enjoins us to appreciate.

What we have seen so far gives us one reason to think that Thoreau believed the catechism's answer regarding our chief end was more or less on target. The catechism says that our chief end involves two responses - enjoyment and glorification. The former roughly captures the passive and reactive aspects of the appropriate response to value. It is a decent stand-in for the complex set of attitudes that a proper awareness of value will include - understanding, awe, invigoration, pleasure, respect, rejoicing. And the idea that our goal includes glorification roughly captures the more active and creative aspects of the appropriate response to value. The sense of "glorify" most likely at work in the religious creed is "to advance the glory of God by faithful action." If we substitute "value" for "God" in this definition, it does a good job of capturing the creative responses to value that Thoreau thinks partly comprise our chief end.

Is it fair to substitute "value" for "God" in the catechism? Since Thoreau understands value to be the worldly manifestation of the divine, I think it is. He writes,

God himself culminates in the present moment, and will never be more divine in the lapse of all the ages. And we are enabled to apprehend at all what is sublime and noble only by the perpetual instilling and drenching of the reality that surrounds us. (97)

This passage expresses Thoreau's view that when we apprehend value, we are apprehending perceptible effects of God. Thoreau also seems to think that the only way we can apprehend the divine is by relating to valuable aspects of the world: "I cannot come nearer to God and Heaven / Than I live to Walden even." (193) Putting these two claims together yields the conclusion that, for Thoreau, contact with value and worldly contact with God are one and the same. God is not just earthly value, but earthly value is all that there is of God for humans to experience. 
Incidentally, this way of understanding the relationship between God and value provides hope that Thoreau's views about evaluating lives can be compelling to religious believers and non-believers alike. Thoreau does frequently refer to God and the divine, and sometimes does so in his discussions about quality of lives. But if the religious aspects of Thoreau's views about evaluating lives are confined to the divine source of all that is valuable, then it may well be that non-believers can safely ignore this aspect of his position. For non-believers who are looking for an answer to questions about quality of life certainly accept that some things are valuable: otherwise they could not think evaluating lives was an important issue. And accepting that some things are valuable may be all that is crucial to Thoreau's argument. Non-believers could thus have good reason to accept Thoreau's account of the value in terms of which lives should be evaluated even if they cannot accept that God is ultimately responsible for all that is good. That is, non-believers could adopt Thoreau's axiology without adopting his metaphysics.

I conclude that Thoreau takes the goal of our lives to be responding properly to what is valuable. Although he is reluctant to explicitly affirm the religious creed that the chief end of life is to enjoy and glorify God, this is not because he thinks that this saying is mistaken. If we understand "enjoy" as a commonsense proxy for the complex of positive reactive responses one who is appropriately aware of value will have, and "glorify" as a commonsense proxy for the many ways in which such a person can creatively respond to what is valuable, and "God" to refer to the value that can be experienced in the world, then the catechism got things right, even if Thoreau was reluctant to say so explicitly.

\section{§2. Prudential Disvalue}

This would be a natural way to conclude our exposition of Thoreau's position concerning prudential value. After all, it might seem that the goal to which we should aspire and what is good for us should be one and the same. But though even a close reading of Walden could give the impression that this is so, there are good reasons for expanding our account. 
One good reason is that, as it stands, the account has some counterintuitive implications. Consider, for instance, two ways a person's life might end. First, a person might die painlessly in her sleep on the eve of her sixtieth birthday. Second, while she sleeps on the eve of her sixtieth birthday, a person's house might catch fire, giving her excruciatingly painful burns of which she dies one week later. It is not hard to imagine that both of these endings leave the person's life with the same amount appropriate response to value - the burn victim's pain could be so bad that it crowds out any awareness of value during the final week of her life. The view articulated so far would thus imply that the first life is no better than the second. But this does not seem right: the burn victim's life would have been better had it had the more peaceful ending. ${ }^{2}$

The problem that this example makes vivid is that if properly responding to value were the only thing in terms of which lives are evaluated, there would be no evaluative difference between a lack of response to good things and experiencing bad things. The absence of value and the presence of disvalue would be prudentially equivalent. But most of us think that encountering something bad is often worse for us than merely failing to encounter something good.

Thankfully, Thoreau seems to have been sensitive to this. A more compelling account of disvalue can be gleaned from his discussion of philanthropy. Here Thoreau warns of the hazards of ministering to those who would accept our charity. In the following passage, though, he assures the reader that his reservations about "doing good" are not an expression of indifference:

All health and success does me good, however far off and withdrawn it may appear; all disease and failure helps to make me sad and does me evil, however much sympathy it may have with me or I with it. (78)

Notice that Thoreau says disease and failure detracts from his life, not that it merely fails to improve his life. His conception of prudential value, therefore,

${ }^{2}$ I have borrowed the general structure of this example from Fred Feldman, Pleasure and the Good Life (Oxford: Clarendon Press, 2004). 
seems to contain a conception not just of the absence of improvement due to the absence of response to value, but also of detriment due to the presence of disvalue.

It is important that Thoreau says that all disease and failure do him evil, for this gives us reason to interpret him as saying that experiencing them is intrinsically bad for a person. Of course, Thoreau would agree that experiencing disease or failure is typically instrumentally bad: when one's awareness is focused on disease and failure, one is unlikely to be responding appropriately to something that is valuable. What's more, our own disease and failure can undermine our capacities to respond to valuable things. But as with all claims about instrumental value, these are just rough generalizations. There can be cases in which what is normally instrumentally bad happens to produce a good outcome. Thoreau offers two relevant cases in point:

We are cheered when we observe the vulture feeding on the carrion which disgusts and disheartens us, and deriving health and strength from the repast. There was a dead horse in the hollow by the path to my house, which compelled me sometimes to go out of my way, especially in the night when the air was heavy, but the assurance it gave me of the strong appetite and inviolable health of Nature was my compensation for this. (318)

In these cases, awareness of disease occasions reflections on something worthy the power of Nature. If Thoreau had meant that all his encounters with disease and failure were instrumentally bad, these cases would thus be straightforward counter-examples. But we can avoid accusing Thoreau of contradicting himself if we understand his claim about awareness of disease and failure to be that it is intrinsically bad. For we can then understand his position to be that these encounters did him evil in one respect, but that this was more than compensated for by the positive value of the thoughts that they engendered, leaving the net effect of the encounter a positive one. ${ }^{3}$

3 The instrumental value of our encounters with disease and failure is important in another respect: it can explain the intuition that a persons life can be improved by the way she responds to disvalue. I return to this point in $\S 3$. 
Finally, although Thoreau only refers to the awareness of disease and failure as making his life worse, I think the Thoreauvian should take these as a rhetorically powerful shorthand for the awareness of disvalue generally. That is, we should say that a person's life is made worse by encounters with anything that makes the world worse, not just disease and failure.

My reason for interpreting Thoreau in this way is partly that it brings his account of prudential disvalue more in line with his account of prudential value. On the view being defended here, our lives are made better by appropriate responses to value in any of its manifestations. Were prudential disvalue limited to awareness of disease and failure, this would be odd, as these are only two of the many ways that the world is made worse. To take an example that mattered a great deal to Thoreau, the institution of slavery in the United States was clearly bad, but it was not clearly an example of disease or failure. ${ }^{4}$ If encounters with such institutions are to detract from one's own quality of life, as seems plausible, then we need to understand prudential disvalue along the lines of prudential value - we need to say that badness of any sort makes our life worse when it enters our experience.

In the next section, we will see how understanding prudential value and disvalue to be parallel in this way has the added virtue of fitting with the underlying rationale for these accounts. But it is also worth noting that this interpretation does not fly in the face of the text. As I mentioned before, when Thoreau makes his claim about the evil of experiencing disease and failure he is not discussing prudential disvalue generally. Instead, he is discussing what consideration he owes to others. With this claim, Thoreau is trying to assure the reader that he is not indifferent to the plight of others, despite his decision to eschew conventional ways of "doing good." Given this context, it makes sense to interpret Thoreau as talking

4 There might be a sense in which slavery was a failure: it was a failure to respond appropriately to the value of the people who were enslaved. In this sense, it may well be that any bad that is caused by humans counts as a failure. If in addition there is a sense in which any bad that occurs naturally counts as an instance of disease, then we could take Thoreau's claim that awareness of disease and failure are prudential evils at face value, since "disease and failure" would then refer to all badness that exists. 
specifically about features of human lives that make the world worse, since it is these features that philanthropists aim to redress. And disease and failure are apt tropes for the sufferings and disappointments of others that conventional morality suggests have a claim on us. Or, in the language we have been using here, disease and failure capture the range of disvalue that human lives can manifest. So while Thoreau does not offer an explicit general account of what makes a person's life worse for her, attributing to him the view that it is encounters with disvalue is consistent with his more focused statement on that issue.

\section{§3. The Argument: Prudential Value as Evaluative Success}

Fair enough, one might think, Thoreau believes that anything that directly contributes to a person's life does so in virtue of its being an appropriate response to value, and anything that directly detracts from a person's life does so because it is the experience of disvalue. But does he offer any reason to believe that this is true? Does he give any argument that should lead someone who doesn't already agree with him to accept that these are the goods and evils in terms of which the quality of their life is measured?

Even sympathetic readers of Walden might suspect that the answer is no. For one thing, Walden is hardly replete with arguments. Thoreau's main aim is to inspire, not deduce.

Indeed, there are points at which Thoreau suggests that providing reasons and arguments could be more of a hindrance than a help when it comes to understanding what living well consists in.

How could youths better learn to live than by at once trying the experiment of living? ... If I wished a boy to know something about the arts and sciences, for instance, I would not pursue the common course, which is merely to send him into the neighborhood of some professor, where anything is professed and practised but the art of life.... (51) 
If you want evidence that what makes a life good is properly responding to what is valuable, we can imagine Thoreau replying, go out and try it. The proof of the view is in the living of it.

I confess to finding this response quite compelling. When I focus my attention on what I believe to be valuable around me, and then imagine a life dedicated to responding to it appropriately - to appreciating it, understanding it, being swept up in it, creating more of it, and so on - that life seems eminently attractive. And when I think of what I wish for my daughters, I find it difficult to want more than that they live such a life. I can't but imagine that if we succeed in living such a life, we will find it rewarding and fulfilling, and will be able to give a powerful justification for our finding it so.

But Thoreau can offer more than just intuitive support. He provides at least the broad outlines of a theoretical argument for his view. And with some elaboration, it can be made quite compelling.

A key to the argument I have in mind can be found in the following sentence:

I went to the woods because I wished to live deliberately, to front only the essential facts of life, and see if I could not learn what it had to teach, and not, when I came to die, discover that I had not lived. (90)

Notice the tight connection Thoreau posits between failing to front the essential facts and failing to live. Given our previous interpretation of Thoreau's reference to "facts" and "reality" as references to value, this is really to posit a close connection between failing to respond appropriately to value and failing to live. What Thoreau seems to be claiming here is that a life lived without appropriately responding to value will not be any kind of life for us. Such a life may contain a lot of biological functioning, of course, but it will lack the qualities that are necessary for the kind of life that creatures capable of understanding what is worthy ought to live. Thus, we can imagine Thoreau claiming that appropriate response to value is the measure of a life like ours because responding to value is essential to what it is to live a life like ours. "To be awake," as he says, "is to be alive." 
Why think that responding to value is so central to living the kind of life that is appropriate for creatures like us? Thoreau's answer seems to be that responding to value is not just something we can do, it is what makes us the kind of creatures we are. We aren't just creatures that happen to be able to self-consciously and reflectively evaluate things, our ability to do this is essential, at least for the purposes of deciding how to live. Thoreau says as much while discussing what it would take for his neighbors to stop living the life that they currently live and start living the life that would be good for them. First, they would need to realize that what they are currently doing is "closing their eyes and slumbering, and consenting to be deceived by shows," with the result that their life "is built on purely illusory foundations." Then they would need to recognize that it is their nature to respond appropriately to what is "real." He makes this latter point with a short parable:

I have read in a Hindoo book, that "there was a king's son, who, being expelled in infancy from his native city, was brought up by a forester, and, growing up to maturity in that state, imagined himself to belong to the barbarous race with which he lived. One of his father's ministers having discovered him, revealed to him what he was, and the misconception of his character was removed, and he knew himself to be a prince. So soul," continues the Hindoo philosopher, "from the circumstances in which it is placed, mistakes its own character, until the truth is revealed to it by some holy teacher, and then it knows itself to be Brahme."(96)

We live in a culture, Thoreau is saying, that leads us to mistake our true nature. ${ }^{5}$ Although most of us do not see it, we are divine, and being divine, the appropriate life for us is one dedicated to what is "sublime and noble."

\footnotetext{
${ }^{5}$ While the invocation of human nature here may strike some biologicallyinformed philosophers as problematic, it needn't be. The Thoreauvian can follow the lead of contemporary neo-Aristotelians, and claim that 'human nature' is not a set of necessary and sufficient conditions for being a member of the species homo sapiens, but instead provides the criteria for being a non-defective example of the human form of life. See Philippa Foot, Natural Goodness (Oxford: Oxford University Press, 2001) and Michael Thompson, "Apprehending Human Form," Royal Institute of Philosophy Supplement 54 (2004): 47-74.
} 
In broad outline, then, we might put the overall argument as follows. We are evaluative creatures: our ability to self-consciously and reflectively evaluate things makes us the kind of creatures we are. The point of all this evaluation is to determine what is worth pursuing so that we can pursue it, and what is worth avoiding so that we can avoid it. As evaluative creatures, we are aimed at value, and away from disvalue. Thus, for evaluative creatures like us, success in living consists in hitting the target at which we are aimed - getting ourselves in the right relationship to what is valuable; and failure consists not separating ourselves from what we are trying to avoid - in being sullied by the mean or ugly or base.

The Thoreauvian argument I have sketched turns on a particular view about the functional structure of the capacity that makes us evaluative creatures. A central premise is that this capacity is aimed at responding appropriately to value and avoiding disvalue. And while this is a natural thought, it is not obviously true. To see why there is room for doubt, let us assume that our cognitive capacities are partly the product of evolution: what cognitive capacities we have is determined by the structure of our brains, and the structure of our brains is partly determined by evolutionary forces that operated on our ancestors. If we were to grant that our evaluative capacity is an adaptation, though, the Thoreauvian might have a problem. For if this capacity has the structure it does because it solved some particular adaptive problem, its functional structure would seem to depend on the details of how it solved those problems. And it is possible that these solutions were selected in virtue of something other than their providing appropriate responses to value. To take just one example, consider aesthetic judgments about female human bodies. Some evolutionary psychologists have argued that these judgments are typically the deliverances of a cognitive mechanism that solved the problem of mate selection, and that it was selected for because it provided our male ancestors with a motivation to mate with partners with a hip-to-waist ratio that was correlated with fertility. ${ }^{6}$ If so, this arguably evaluative mechanism seems to be

${ }^{6}$ See, for example, Devendra Singh, "Adaptive Significance of Waist-to-Hip Ratio and Female Physical Attractiveness," Journal of Personality and Social Psychology, 65 (1993): 293-307. 
aimed at responding appropriately to a woman's ability to produce offspring rather than to her beauty.

Thoreauvians should respond to this challenge by denying that our evaluative capacity is an adaptation. What distinguishes our evaluative capacity from such adaptations is that, in the language of cognitive science, it is not 'modular.' The exact definition of a modularity is a matter of dispute, but there is broad agreement that modular cognitive mechanisms have at least two features: first, they operate outside of conscious awareness and voluntary control; and second they are domain-specific in the sense that they only deal with a narrow range of subject matter. To continue with our example, the evolutionary psychologists who believe that there is a mate attractiveness mechanism believe that its sensitivity to a particular waist-to-hip ratio is something that we are not aware of and that we could not override if we choose to. Moreover, it produces verdicts about the attractiveness about only the female human form. The capacity that makes us evaluative creatures in the Thoreauvian's sense is clearly not like this. When we evaluate something, we are often aware of what considerations are informing our evaluations and we have control over whether and how we will allow these considerations to inform our judgments. And the domain of our evaluative capacity is as general as it could be: it delivers verdicts about anything that can be evaluated.

These differences between our evaluative capacity and modular adaptations lead to different ways of understanding their functional structure. The fact that the operation of a modular mechanism is unconscious and involuntary makes it natural to understand its function as being a matter of the specific evolutionary purpose it served in the Pleistocene. But when it comes to non-modular capacities such as our evaluative capacity, this is no longer plausible, for at least two reasons. First, since our evaluative capacity is a domain-general capacity, it is unlikely that there is a specific adaptive problem whose solution explains its existence. It is unlikely, therefore, that it had a specific evolutionary purpose that could be used to ground a claim regarding its function. And secondly, the fact that we can control how our evaluative capacity operates means that we can bend it to our 
own use. As a result, it makes much more sense to see its function as a matter of what we use it to do, no matter what its evolutionary history is.

What do we use our evaluative capacity for? When we are being self-conscious evaluators, we focus our attention on specific things so that we may better weigh their attributes and determine whether they are worth pursuing. ${ }^{7}$ When we do so, we interpret the resulting desires as aimed at accurately reflecting what is valuable. We don't just discover that we happen to desire something, we judge that what we desire is in fact desirable. We take ourselves to be searching for and to be guided by the goodness of our options. As a result, when we take something to be desirable, we take this to mean that it ought to be responded to in certain ways - that it ought to be appreciated, enjoyed, protected, created, and so on. Since we employ our evaluative capacity in this way, there is an important sense in which this capacity is aimed at responding to value.

None of this is to deny that modular mechanisms might well be closely connected to our evaluative capacity. Indeed, it is plausible that many of them supply some of the considerations in light of which we make our evaluations of things. If so there is a sense in which we might understand these lower-level capacities as "evaluative." But since the capacity that makes us evaluative creatures in the Thoreauvian's sense is something that exists over and above these lower-level mechanisms, we can understand its teleology as being qualitatively different from theirs.

This way of addressing the evolutionary challenge also allows us to disambiguate two ways in which we might understand a person's success in so far as she is an evaluative creature. One way is the way I have been understanding it so far: responding appropriately to value and avoiding disvalue. But we might also think of evaluative success as a matter of having one's evaluative responses fit the objects that elicit them. This would involve not only admiring what is admirable and

${ }^{7}$ As Foot observes, "while animals go for the good (thing) that they see, human beings go for what they see as good." Op cit., p. 56. 
creating what is worthy, but also being disgusted by what is disgusting, being saddened by what is tragic, being angry at what is outrageous and so on.

It should be clear that evaluative success in the second sense is a poor candidate for an explanation of prudential value. This conception would imply that a person's life is directly improved by encountering the disgusting, tragic and immoral, provided that she respond to them with the attitudes they warrant: disgust, grief, and outrage. But this is not plausible. No one assuages a person who has been betrayed by reminding him that he is better off for having been given an opportunity to be appropriately outraged. ${ }^{8}$

Compatibility with our intuitions about prudential value is not the only reason for Thoreauvians to rely on the conception of evaluative success we have been using so far, however. The notion of evaluative success in the sense of responding appropriately to value and avoiding disvalue is derived from the teleology of what I have been calling our evaluative capacity, whereas the notion of evaluative success as having fitting evaluative responses is derived from the teleology of the lower-level - and possibly modular - mechanisms that provide inputs into that capacity. Since the Thoreauvian argument is based on the fact that we are evaluative creatures, it is appropriate for us to appeal to the conception of evaluative success connected to the overall teleology of our evaluative system rather than the one based on the teleology of its inputs considered piecemeal.

The Thoreauvian's claim that insofar as we are evaluative creatures we are aimed at responding appropriately to value and avoiding disvalue thus seems warranted. What remains to be argued for is that this aspect of our natures is in some important sense central for the purpose of understanding our good.

A first step towards making this case is to recognize that there are many kinds of things we are, but success at being some of these kinds of things is irrelevant to the quality of our lives. To see an example of an account of well-being that founders for missing this point, consider George Sher's version of perfectionism. Sher starts

${ }^{8}$ Simon Keller's account goes astray here. See his "Welfare as Success," Noûs 43 (4): 656-683. 
where the Thoreauvian does: he claims that lives should be evaluated in terms of the successful exercise certain capacities. But his answer to the question, 'Which capacities?' is more capacious than the Thoreauvian's. He claims that the relevant capacities are all those that are "fundamental" human capacities, i.e. capacities whose exercise for humans is "near-universal and near-inescapable." His hope is that this will have the consequence that the human good consists in knowledge, rational activity, close personal relationships, moral goodness, the development of one's talents, and the appreciation of true beauty. The trouble is that there seem to be many capacities whose exercise is nearly universal and nearly inescapable among humans, but which are not directly aimed at anything on Sher's list of goods. Again, our biological capacities provide troublesome examples. For instance, humans nearly universally and nearly inescapably exercise reproductive capacities that are aimed at producing offspring. But having offspring is not a plausible intrinsic human good. Consider a man who has contributed to a sperm bank. Few would hold that his life goes better the more women are successfully impregnated with his sperm.

The lesson the Thoreauvian takes from this is that although we are biological creatures, the degree to which we succeed biologically is not an intrinsic measure of our lives. More generally, we can conclude that any account that proposes that we evaluate our lives in terms of how successful we are at being the kind of creatures we are has to isolate one (or some subset) of the kinds of things we are, and argue that successfully being this kind of thing is what our good consists in.

But why single out our being evaluative creatures? The Thoreauvian's answer is to point out that in asking what our good consists in and using the answer to direct our choices we are acting out of our evaluative natures. We are using our capacity to self-consciously evaluate the range of things we might aim at, and we do so with the intention of pursuing that which is best. It is as evaluative creatures that we think about our good. In this sense, when we think about our good, our evaluative nature is essential: a creature who asks about its good and uses the answer to

${ }^{9}$ George Sher, Beyond Neutrality, (New York: Cambridge University Press, 1997), p. 202. 
direct its choices is necessarily an evaluative creature. And since it is as evaluative creatures that we deliberate about what is good for us, the Thoreauvian can say, it is our success as evaluative creatures that constitutes the standard that this deliberation answers to.

Of course, we are also using many other capacities when we try to determine what to pursue. We are breathing, for example. But our respiratory capacities are not implicated in our prudential deliberations in the same way that our evaluative capacities are. Most importantly, a creature that theoretically and practically inquires into its own good must be an evaluative creature. Whether it produces energy by oxidation is, by contrast, incidental.

By way of summary, then, we might put the Thoreauvian's positive argument this way. Prudential goodness is teleological: the good of a being consists in the achievement of what it is aimed at. We things who inquire into our own good are necessarily evaluative creatures. Evaluative creatures are aimed at responding appropriately to value and avoiding disvalue. So our good consists in achieving our necessary aim; in the appreciation and creation of what is valuable in the world, and in keeping ourselves separate from that which makes the world worse.

\section{\$4. Conclusion}

It will take a good deal more work to get from this account of prudential value to a full Thoreauvian account of well-being. One outstanding issue is that we need a Thoreauvian account of objective value. Until we know what in the world is worth enjoying and glorifying, what is worth avoiding, and why, we will not have a complete, substantive understanding of the good life. In this respect, the Thoreauvian account of prudential value is analogous to consequentialist accounts of moral rightness. Consequentialism, too, posits a conceptual connection between its analysand and a kind of value, without specifying what particular properties instantiate this kind. As a result, consequentialism itself does not yield a complete, substantive account of what acts are morally right. 
Although I think that Thoreau has an interesting axiology to offer, this is not the occasion to develop it. For the time being, then, the account of prudential value remains somewhat formal. But as is the case with consequentialism, the formal Thoreauvian account of prudential value still has theoretical bite. I'd like to conclude by pointing to a few of the ways that this account can contribute to current discussions about well-being.

The Thoreauvian account of prudential value will figure in an objective account of well-being. This is because it is incompatible with the central tenet of subjective accounts. On the Thoreauvian view, whether a person's subjective response to something adds to their quality of life depends on the nature of that thing: whether enjoying, or desiring, or being satisfied with a thing is good for you depends on whether the thing is in fact valuable. Subjectivists about well-being, by contrast, are committed to the idea that a person's response to a thing is what makes it good for her, irrespective of what the object of this response is. This aspect of subjectivism is the source of many counterintuitive implications. These are well-rehearsed elsewhere, so I will resist the temptation to catalogue them here. Instead, I will concentrate on the promise a Thoreauvian account holds visà-vis some of its objectivist alternatives.

A weakness of some objective accounts is that they have scant claim to being theories. In particular, the defenders of "objective list" accounts simply list goods that make a person's life better. This is not to say that they don't offer arguments for their accounts; they do. Typically, they try to show how their list of goods fit with our pre-theoretical judgments about what contributes to, and detracts from, the quality of a life. What they do not do, however, is provide any explanation of why the several things that are putatively good for us are good for us. ${ }^{10}$

10 Defenses of objective list theories can be found in: Richard J. Arneson, "Human Flourishing versus Desire Satisfaction." Social Philosophy and Policy, 16 (1999): 113-142; and Thomas Scanlon, "Value, Desire, and Quality of Life," in The Quality of Life, ed. Martha C. Nussbaum and Amartya Sen (Oxford: Clarendon Press, 1993), pp. 185-200; David Brink, Moral Realism and the Foundations of Ethics 
The problem with objective list accounts is not just that they fail to satisfy those who hoped to understand prudential value in addition to being able to identify it. The problem is also that they have a difficult time justifying the reliability of the intuitions on which the arguments for them depend. For the obvious strategy for justifying our intuitions about what is prudentially valuable is to show that they are responding to the property that makes the things that are good for us good for us. But on these objective list accounts, there is no such property. So it is difficult to see how their defenders can respond to challenges from those whose coherent prudential intuitions differ from theirs, or from those who argue that the intuitions being relied upon on are not evidence of objective prudential value but instead some other property - the property of satisfying some particular set of desires, for instance, or of producing a positive metal state in particular people.

I have noted my conviction that Thoreau's position can hold its own in a contest of intuitions. But because Thoreau's is not an objective list theory, it does not stand or fall on the outcome of such contests. The Thoreauvian has an explanation of why certain kinds of pleasures, knowledge, relationships, achievements, and so on are good for us: they are good for us in virtue of being ways of appropriately responding to something that is valuable. We thus can not only identify what things are good for us, but also understand what it is about them that makes them good. This is itself an advance. Moreover, we have resources to draw on in responding to those who challenge the accuracy of our intuitions or what they are evidence of. If we disagree about whether all accomplishments contribute to the quality of a person's life, for instance, the Thoreauvian can do more than appeal to her intuition that evil accomplishments do not: she can also explain that a person's evil accomplishments fail to improve his life because they are inappropriate responses to value. Granted, for all we have said here, the problem of theoretically unsupported value claims may re-emerge for the Thoreauvian at the level of objective value. Theoretical explanations must come to an end somewhere. But just as the unity of consequentialist accounts regarding rightness constitutes one advantage over Rossian pluralism, the

(Cambridge, Cambridge University Press, 1989), Chapter 8; John Finnis, Natural Law and Natural Rights (Oxford: Clarendon Press, 1980), pp. 85-90. 
systematicity of the Thoreauvian account at the level of prudential value counts as a point in its favor. ${ }^{11}$

Not all objective theories simply list things that are putatively good for us. Perfectionist accounts try to link the things that are good for us with human nature. The more excellent an example of a human being one is, these theorists hold, the higher one's quality of life. Perfectionists thus have an explanation of why the things that are good for us are good for us: things that are good for us are so because they constitute the fulfillment of our nature. Thoreau's position is similar to such accounts, but there is a crucial difference. Thoreau's position does not appeal to all of human nature, but instead to the nature of evaluative creatures. The reason this is important is that it is hard to imagine that everyone will care to develop all aspects of their nature. A person might be convinced that becoming more muscular, say, will make her a better example of a human being, but nevertheless lack any intrinsic interest in improving her muscularity. To many, it seems a mistake to say that something could be intrinsically good for a person even if they have no interest in it - indeed, even if they positively wish to avoid it. Our own good is not something that can be alien to us in this way, they say.

This problem has been used to challenge not just perfectionist theories, but all accounts according to which a person's attitudes are not the determinants of what is prudentially valuable for her. Thoreau's position, however, shows that prudential value can be tied to a person's concerns without embracing subjectivism. ${ }^{12}$

\footnotetext{
11 As Brad Hooker claims, "a theory which specifies an underlying rationale for our various general principles is, other things being at least roughly equal, better than one which doesn't." "Ross-style pluralism versus rule-consequentialism," Mind 105 (1996): 536.

${ }^{12}$ In this respect, it has an advantage over several contemporary accounts that are extensionally similar (although not identical) to Thoreau's. See for instance, Thomas Hurka, The Best Things in Life: A Guide to What Really Matters (Oxford: Oxford University Press, 2011); and Stephen Darwall, "Valuing Activity," Social Philosophy and Policy, 16 (1999): 176-196.
} 
The core of the problem is that when we remember that we are trying to understand what contributes to the quality of a person's life for her, it is appealing to understand the standards by which that quality is judged as originating in her. ${ }^{13}$ The standards by which we judge a subject's well-being, it is thought, must not be standards that have their source in some external and independent authority to which she is then held accountable for her own sake; they must be intimately connected to her, and more particularly, to what she cares about.

The Thoreauvian account shows that we need not identify a person's good with what she cares about in order to do justice to this thought. For on this account, our being judged by the degree to which we appropriately respond to value is a consequence of something we do - namely, it is a consequence of our exercising our evaluative natures. In self-consciously deliberating about what is worth pursuing and using the answers to guide our action, we are taking on the aim of getting ourselves into the right relationship with what is good. The Thoreauvian thus shares at least this much with the Kantian: each explains the authority of the relevant standards - prudential standards and moral standards, respectively - by showing that they are the standards one commits oneself to when one engages in the activity under inquiry. So while there is a sense in which the quality of our lives is measured in terms of our cares and desires, it is not that the content of our cares and desires determines what is good for us. Instead, Thoreau's insight is that it is what our cares and desires are aimed at having us achieve - a proper response to what is good in the world - that sets the measure of our lives. ${ }^{14}$

13 See, for example, L.W. Sumner, Welfare, Happiness, and Ethics (Oxford: Glarendon Press, 1996), pp. 162-166.

${ }^{14}$ I would like to thank Kirsten Egerstrom, Charles Goodman, Christopher Gowans, Bob Guay, John Hacker-Wright, Max Pensky and several anonymous referees for their helpful comments on earlier drafts of this paper. 